\title{
RGO/Nylon-6 Composite Mat with Unique Structural Features and Electrical Properties Obtained from Electrospinning and Hydrothermal Process
}

\author{
Hem Raj Pant ${ }^{1,2}$, Bishweshwar Pant ${ }^{1}$, Chan Hee Park', Han Joo Kim¹, Dong Su Lee ${ }^{3}$, Leonard D. Tijing ${ }^{4}$, \\ Bo Sang Hwang ${ }^{4}$, Hak Yong Kim ${ }^{5}$, and Cheol Sang Kim ${ }^{1,4 *}$ \\ ${ }^{1}$ Department of Bionanosystem Engineering, Chonbuk National University, Jeonju 561-756, Korea \\ ${ }^{2}$ Engineering Science and Humanities Department, Institute of Engineering, Pulchowk Campus, \\ Tribhuvan University, Kathmandu, Nepal \\ ${ }^{3}$ Institute of Advanced Composite Materials, Korea Institute of Science and Technology, Wanju 565-902, Korea \\ ${ }^{4}$ Division of Mechanical Design Engineering, Chonbuk National University, Jeonju 561-756, Korea \\ ${ }^{5}$ Department of Organic Materials and Fiber Engineering, Chonbuk National University, Jeonju 561-756, Korea
}

(Received September 26, 2012; Revised November 2, 2012; Accepted November 5, 2012)

\begin{abstract}
In this work, the reduced graphene oxide (RGO) sheets were effectively uploaded through nylon-6 fibers using combined process of electrospinning and hydrothermal treatment. Good dispersion of graphene oxide (GO) with nylon- 6 solution could allow to upload GO sheets through nylon-6 fibers and facilitate the formation of spider-wave-like nano-nets during electrospinning. GO sheets present on/into nylon-6 spider-wave-like nano-nets were further reduced to RGO using hydrothermal treatment. The impregnated GO sheets into nylon-6 nanofibers and their reduction during hydrothermal treatment were confirmed by FE-SEM, TEM, FT-IR and Raman spectra. The electrical characteristics of pristine nylon-6, GO/nylon-6 and RGO/nylon-6 nanofibers were investigated and it was found that RGO/nylon-6 composite mat had better electrical conductivity than others. The formation of spider-wave-like nano-nets as well as indirect route of incorporation of RGO sheets on electrospun nylon-6 mat may open a new direction for future graphene/polymer electronics.
\end{abstract}

Keywords: Electrospinning, Hydrothermal, Graphene oxide, Nylon-6, Conductivity

\section{Introduction}

In the recent years, polymer nanofibers have found a broad range of applications in the fields of electronics, catalysis, protective clothing, filtration, bioengineering and biotechnology [1-3]. Electrospinning is a simple technique for the fabrication of nanofibers from various polymers which is based on the principle of electrohydrodynamic jetting of polymer solution that drives the solution to be

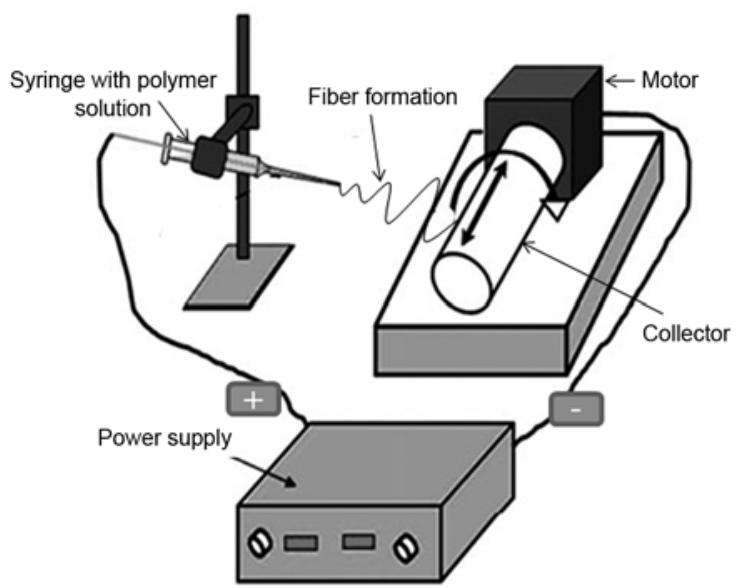

Figure 1. Schematic diagram for a simple electrospinning set-up.

*Corresponding author: chskim@jbnu.ac.kr stretched into fibers (Figure 1). The fabrication of onedimensional semiconducting nanofibers using electrospinning has attracted great attention because of their promise in large-area electronic device applications [4-6]. Fabrication of polymeric fibers up to true nano-size $(<50 \mathrm{~nm}$ in diameter) [7] with high aspect ratio has offered wide opportunities to construct more efficient interfaces for large-area electronics if they have electrical conductivity. Authors' previous reports show that nylon- 6 is a potential candidate for the fabrication of true nanofibers (having high aspect ratio) in the form of spider-wave-like mat by varying process/material parameters during electrospinning [8-14].

Nylon-6 is a polyelectrolyte which has good physical and mechanical properties [13]. However, its electrical conductivity is very low. Therefore, nylon-6 nanofibers can be readily applicable if their electrical conductivities were enhanced [15]. The electrical conductivity of nylon-6 nanofibers can be significantly improved by adding different foreign materials such as metal nanoparticles (NPs), semiconductor NPs, carbon nanotubes, graphene etc [16-18]. Out of them graphene, a flat monolayer of sp2-bonded carbon atoms, is a promising material due to its unique characteristics such as high electronic conductivity, large specific surface area, and high mechanical strength [19-21]. However, weak dispersion of graphene in polymer solution makes electrospinning difficult and suitable amounts of it could not be uploaded on electrospun fibers. Compared to graphene, graphene oxide (GO) can be easily dispersed with polymer solution and more amount of GO can be loaded on/into fibers during 
electrospinning. Authors' previous report not only showed that the sufficient amount of GO was well dispersed in nylon-6 solution but also showed that the interaction of GO sheets with nylon- 6 molecules could produce large number of spider-wave-like nano-nets [14]. Due to the greater dispersion of the GO compared to graphene in polymer solution, it does not sufficiently hinder the spinability of nylon- 6 solution and provide the sufficient sites for polymeric molecules to interact with it by the formation of hydrogen bond. However, poor conductivity of GO could not enhance the electrical conductivity of composite mat of nylon-6. Therefore, reduction of GO sheets is essential to increase the electrical conductivity of nylon- 6 composite mat.

In this study, hydrothermal reduction of GO sheets on $\mathrm{GO} /$ nylon- 6 composite mat was carried out to increase the electrical conductivity of nylon- 6 nanofibers. The morphological and electrical characteristics of the as-prepared RGO/nylon6 composite nanofibers were investigated. We are expecting this study may pave the way for indirect uploading of RGO on/into electrospun polymeric fibers and their potential application for electronic devices and biosensors.

\section{Experimental}

Synthetic graphite (Sigma Aldrich) was used to prepare GO using modified Hummer's method [22,23]. Experimentally, $5 \mathrm{~g}$ of graphite powder and $125 \mathrm{~m} l$ of concentrated sulfuric acid was taken into $500 \mathrm{~m} l$ three-necked round bottom flask followed by the addition of solid potassium permanganate $(17.5 \mathrm{~g})$ at $0^{\circ} \mathrm{C}$ (ice bath). The mixture was stirred for $3 \mathrm{~h}$ at $35^{\circ} \mathrm{C}$ then diluted by adding sufficient amount of distilled water at $0{ }^{\circ} \mathrm{C}$ ice bath. $\mathrm{H}_{2} \mathrm{O}_{2}(30 \mathrm{vol} \%$ in water from Aldrich $)$ was added until the bubbling of the gas was completed. The washed acid-free product was dried under vacuum at $70^{\circ} \mathrm{C}$ for two days. Polymer blends were prepared by simply mixing of $125 \mathrm{mg}$ of as-prepared GO with $25 \mathrm{~g}$ of $22 \mathrm{wt} \%$ nylon-6 $(\mathrm{Mw}=35000$, Kolon, Korea) in 4:1 (by weight) formic acid/acetic acid solvent system.

Electrospinning was carried out at $18 \mathrm{kV}$ and $16 \mathrm{~cm}$ distance between the collector and the tip of the syringe. Temperature and humidity were $28^{\circ} \mathrm{C}$ and $34 \%$, respectively. The fibers were collected on polyethylene sheets attached on the surface of rotating drum. After vacuum drying for $24 \mathrm{~h}$, the mats were used for hydrothermal treatment. For the hydrothermal reduction of $\mathrm{GO}$ on the surface of nanocomposite fibers, electrospun $\mathrm{GO} /$ nylon- 6 nanocomposite matrices $(5 \times$ $5 \mathrm{~cm}$ ) with $70 \mathrm{~m} l$ distilled water and $20 \mathrm{~m} l$ ethanol was taken into a Teflon crucible. The Teflon crucible was kept inside a stainless steel autoclave for hydrothermal treatment at $125^{\circ} \mathrm{C}$ for $3 \mathrm{~h}$ and then naturally allowed to cool at room temperature. Then the mat was washed several times by distilled water and was vacuum-dried for $24 \mathrm{~h}$ at $30^{\circ} \mathrm{C}$.

The morphology of the different mats was observed by using field-emission scanning electron microscopy (FE-
SEM, Hitachi S-7400, Japan) and transmission electron microscopy (TEM, JEM-2010, JEOL, Japan). For TEM observation, fibers were directly deposited onto a TEM grid during electrospinning. Formation of $\mathrm{GO} /$ nylon- 6 and $\mathrm{RGO} /$ nylon-6 nanocomposite was determined by FT-IR spectroscopy (ABB Bomen MB100 spectrometer, Canada) and Raman Spectroscopy (RFS-100S, Bruker, Germany). To study the electrical properties of as-prepared mats, a current-voltage (I-V) characteristic was measured in two-probe configuration using Keithley 2400 semiconductor characterization system. The synthesized mats were cut into small piece (same dimension) and they were contacted by $25 \mu \mathrm{m}$ thick $\mathrm{Au}$ wires with an assistance of silver paste. The thickness of pristine nylon- 6 , GO/nylon- 6 , and $\mathrm{RGO}$ /nylon- 6 mats was $0.041,0.032$, and $0.034 \mathrm{~mm}$, respectively, which was measured using a digital micrometer.

\section{Results and Discussion}

For fine electronic devices, conductive polymeric fibers $<50 \mathrm{~nm}$ in diameter (true nanofibers) are more desirable as they provide high aspect ratio. Therefore, the techniques to fabricate such true polymeric nanofibers with electrical properties are potential in electronic devices. The presence of sufficient amount of true nanofibers in the form of spiderwave-like nano-nets was observed from the FE-SEM images of GO/nylon-6 mat as shown in Figure 2. For pristine nylon6 mat (Figure 2(a)), the fibers appear well-defined without any spider-wave-like nano-nets. However, the mat obtained from the blend solution of nylon- 6 and GO showed that large amount of spider-wave-like nano-nets are formed throughout the mat. The formation of spider-wave-like nanonets might be probably due to the fast solvent degradation of nylon- 6 caused by well dispersed GO sheets through the electrospinning solution which was explained in authors' previous report [14]. The solvent degradation of nylon-6 (caused by formic acid) might be accelerated when suitable amounts of GO sheets were well dispersed throughout the nylon-6 solution $[11,14]$. Since large amount of solvent degraded ionic oligomer molecules of nylon- 6 were formed during the solution preparation, there might be two fractions of solution (higher and lower molecular weight fractions) during jet whipping. The fraction of lower molecular weight polymer solution could form true nanofibers during phase separation [14]. The proper loading of GO sheets on/into asfabricated fibers was carried out by transmission electron microscopy (TEM). Figure 3(a) shows that pristine electrospun nylon-6 fiber is smooth whereas fiber obtained from blend solution shows that GO sheets were loaded on fibers (Figure 3(b)). Inset of Figure 3(a) shows the size of as-prepared GO sheets. These sheets might be incorporated through thick fibers but not with true nanofibers.

It is reported that GO is better than RGO for nano-filler in polymer composite as it can interact with the functional 

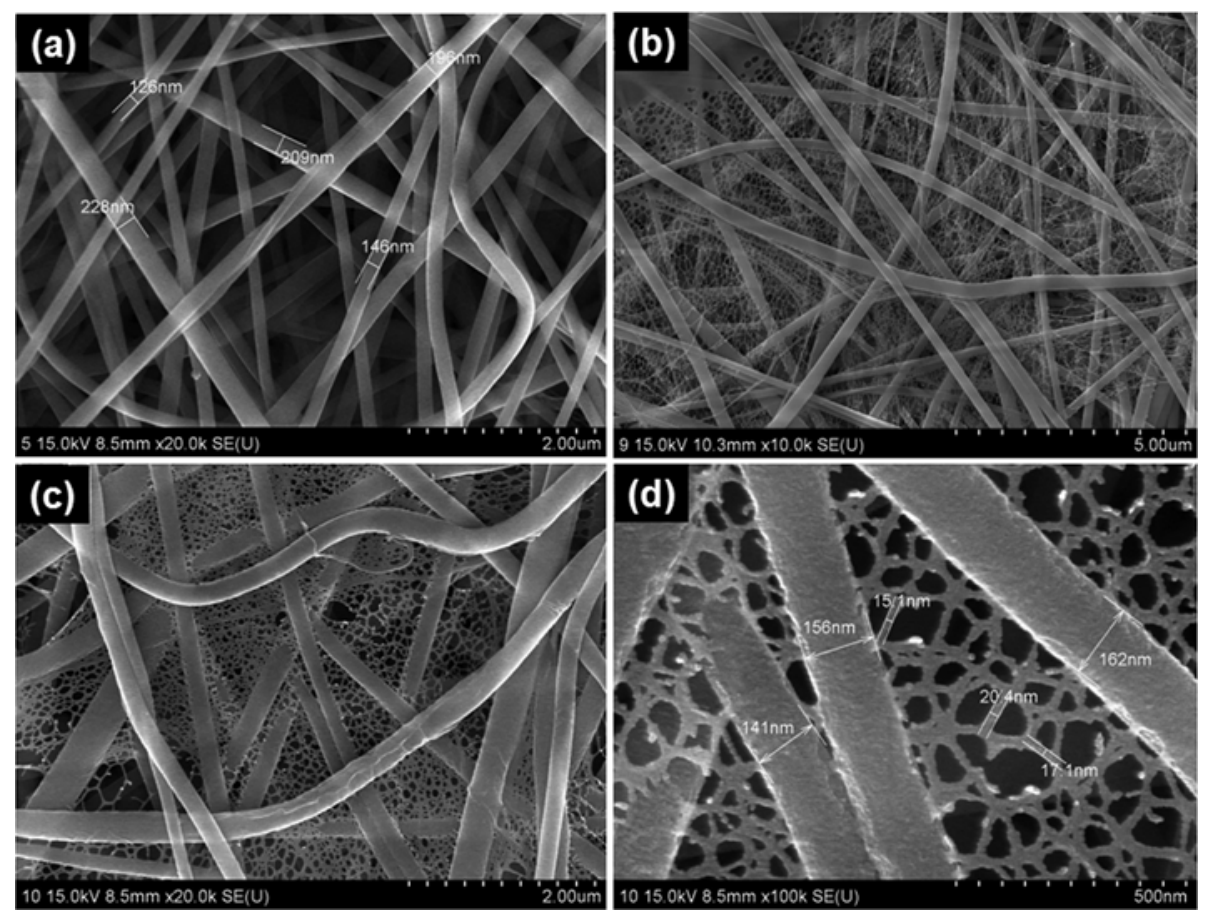

Figure 2. FE-SEM images of (a) pristine nylon-6, (b) GO/nylon-6, (c) RGO/nylon-6 (low magnification), and (d) RGO/nylon-6 (high magnification) mats.
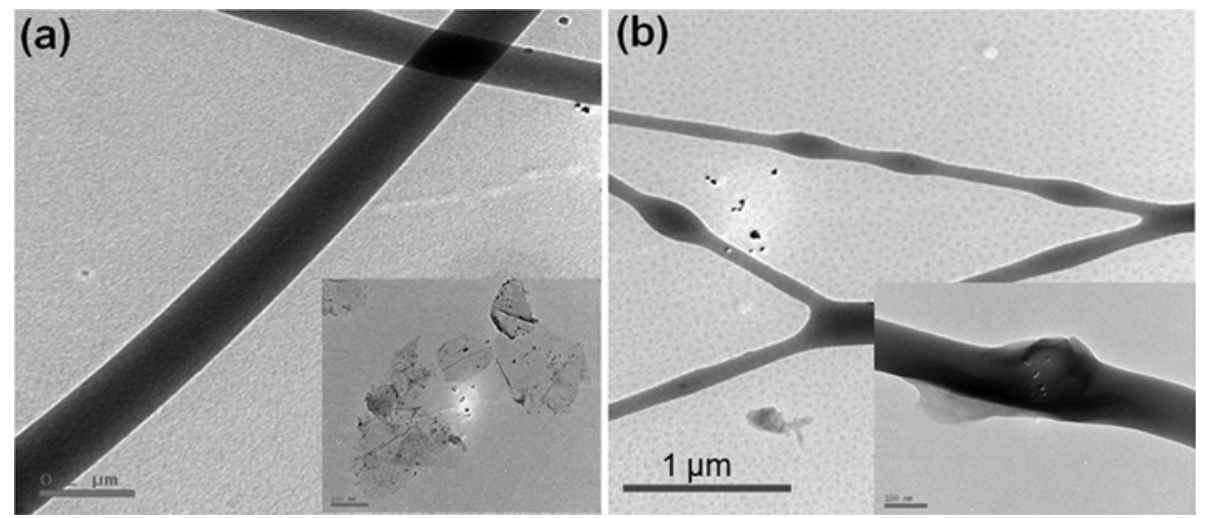

Figure 3. TEM images of (a) pristine nylon-6 (inset is pure GO) and (b) composite GO/nylon-6 mats (inset is high magnification image).

groups of polymeric materials by the formation of hydrogen bonds [24]. The functionalities of GO can easily interact with $\mathrm{CO}$ and $\mathrm{NH}$ groups in nylon- 6 molecules via hydrogen bond and they can be uploaded through fibers during electrospinning [25]. However, for enhancing the electrical conductivity of composite materials, RGO is required. Therefore, GO present in composite nylon-6 mat should be reduced to graphene (RGO) via hydrothermal treatment as described in the literature [26,27]. The functionalities of GO were reduced by alcohol during hydrothermal treatment [28]. Figure 4 shows the FT-IR spectra of pristine nylon- 6 mat and GO/nylon-6 mat before and after hydrothermal treatment. The characteristic peaks of pristine electrospun nylon-6 mat are explained in authors' previous work [13]. Comparing to the pristine nylon- 6 mat, GO or RGO containing mat has no any pronounced changes on the IR spectra which might be attributed by the low content of GO. We observed that the amide II band (at $1545 \mathrm{~cm}^{-1}$ ) became less intense and slightly shifted to higher wavelength when GO is incorporated with nylon-6. The result showed that welldispersed GO sheets could rupture the intermolecular hydrogen bonds of nylon- 6 chain and form new hydrogen bonds between GO and nylon- 6 molecules. The further decreased in the intensity of this band in hydrothermallytreated mat (Figure 4(d)) revealed that hydrogen bonding was decreased due to the formation of RGO. 


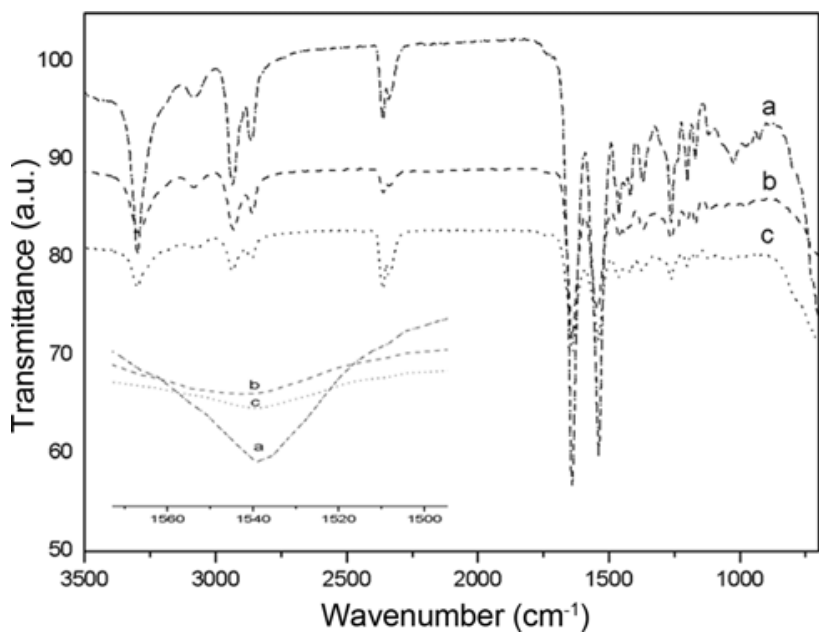

Figure 4. FT-IR spectra of (a) pristine nylon-6, (b) GO/nylon-6, and (c) RGO/nylon-6 mats.

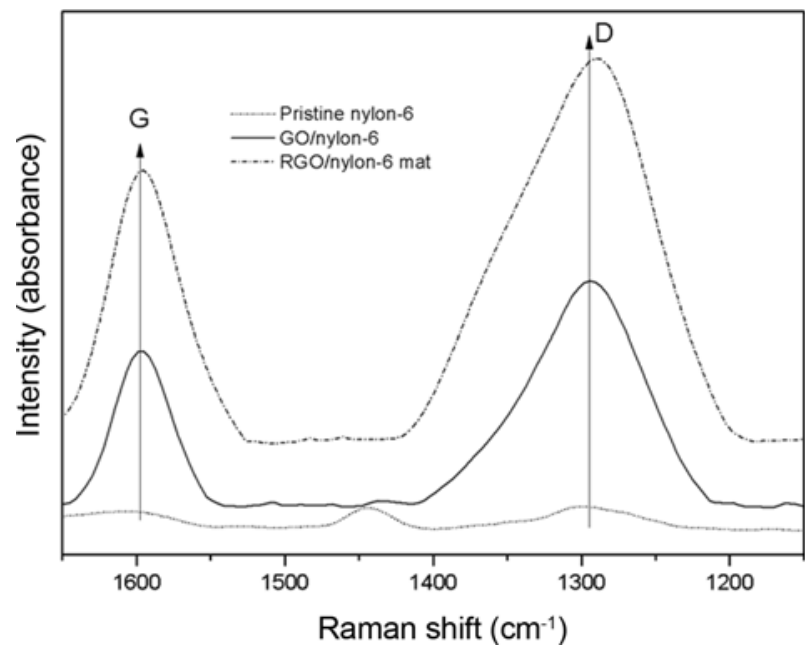

Figure 5. Raman spectra of different mats $(G=G$ band and $D=D$ band).

The presence of GO sheets on composite mat and its reduction during hydrothermal treatment can be determined by Raman spectroscopy. Figure 5 presents the Raman spectra of pristine nylon-6, GO/nylon-6, and RGO/nylon-6 mats. The important Raman bands of pristine nylon-6 were described in our previous work [12]. Comparing to the band of pristine nylon-6, Go/nylon- 6 composite mat clearly showed that there were D-band and G-band of GO sheets (Figure 5) [29]. The ID/IG ratio was increased in hydrothermal treated mat as compared to un-treated mat which indicated the reduction of GO during hydrothermal treatment [30]. Furthermore, the shifting of the spectrum of $\mathrm{G}$ and $\mathrm{D}$ bands towards lower value in RGO/nylon-6 mat (Figure 5) was also an indication of reduction of GO during hydrothermal treatment [30].

Figures 6 and 7 show the electrical properties of pristine

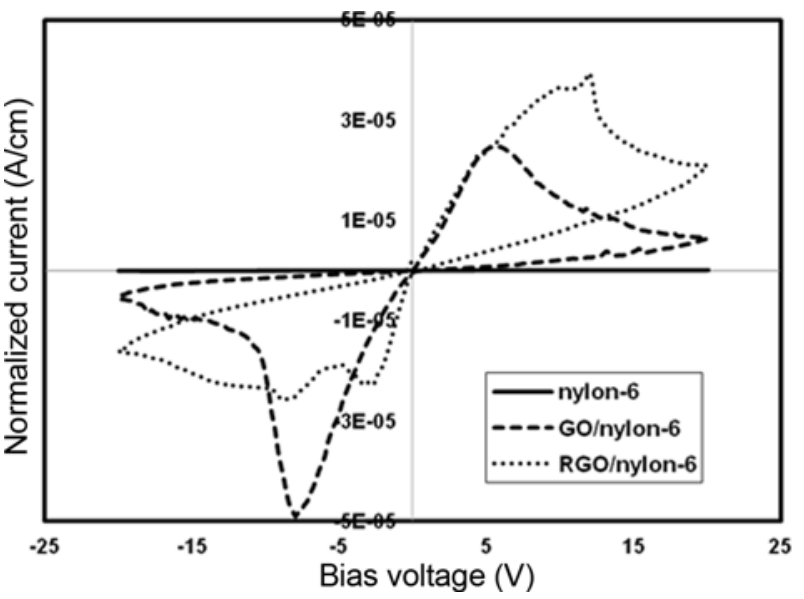

Figure 6. I-V characteristics of pristine nylon-6 and GO/RGO incorporated nylon- 6 electrospun mats.

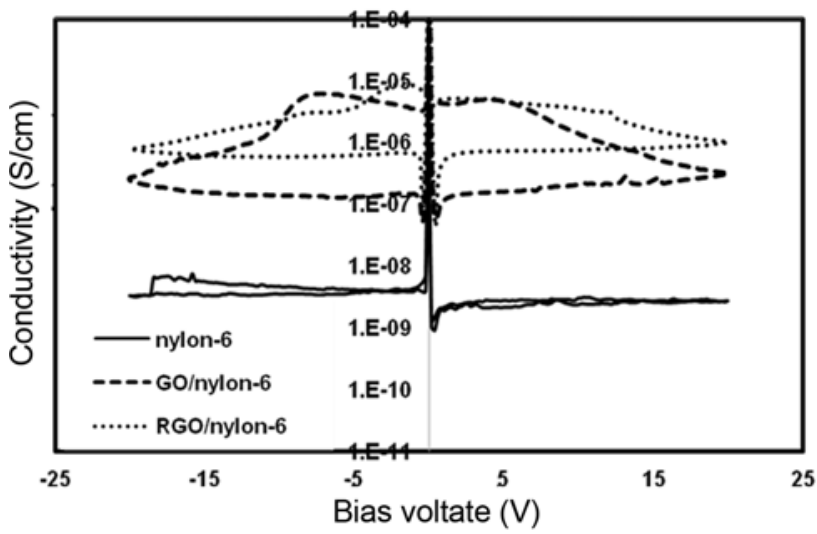

Figure 7. Conductivity as a function of bias voltage for different samples.

nylon-6, GO/nylon-6, and RGO/nylon-6 mats. Different mats with equal dimension were contacted by $25 \mu \mathrm{m}$ thick $\mathrm{Au}$ wires with an assistance of silver paste for currentvoltage (I-V) characterization. The I-V characteristics were measured for the applied bias voltage ranging between -25 to $+25 \mathrm{~V}$ (Figure 6). For better comparison, the current was normalized by the sample dimension $(t w / l)$, where $t$ is the sample thickness, $w$ the width, and $l$ the length of mat. Hysteric behavior was observed for the GO/nylon-6 and the RGO/nylon-6 composite mats by a cyclic voltage sweep. This might be due to trapping sites inside the samples caused by large number of true nanofibers and GO or RGO sheets. Despite the hysteric behavior, the data confirmed that the conductivity of nylon-6 fibers is improved when GO or RGO is incorporated with them. This can be seen more clearly in conductivity, $\sigma=(\mathrm{I} / \mathrm{V})(\mathrm{tw} / \mathrm{l})$, as a function of applied voltage (Figure 7). For RGO/nylon-6 sample, the conductivity is about $1.0 \mu \mathrm{S} / \mathrm{cm}$ at $\mathrm{V}=20 \mathrm{~V}$, which is about 300 times larger than that of the pristine nylon- 6 mat $(\sigma \sim 2.8$ 
$\mathrm{nS} / \mathrm{cm}$ ) and about 3 times larger than that of the GO/nylon-6 composite mat $(\sigma \sim 0.33 \mu \mathrm{S} / \mathrm{cm})$. The better electrical conductivity of $\mathrm{GO} /$ nylon- 6 composite mat compared to the pristine nylon- 6 mat is attributed to the formation of denser true nanofibers (Figure 2(b)) as well as GO sheets which can make better contact among the fibers and can enhance the electrical pathways. Similarly, reduction of GO sheets during hydrothermal treatment could also enhance the electrical conductivity of RGO/nylon- 6 mat.

The increased conductivity in the composite mats suggests that GO or RGO loading boosts the electron conduction path. Moreover, possibility of bridging between the nylon- 6 nanofibers due to the spider-wave structure and GO/RGO sheets can increase the amounts of charge carrier and reduces hopping distance of conduction electrons which favors percolation phenomenon. Jeong et al. [31] also observed the similar result when MWNTs were incorporated through electrospun nylon fibers. On the basis of our experimental analysis, we can conclude that reduction of GO sheets present on electrospun nylon-6 fibrous mat play a significant role on the electrical properties of nylon- 6 composite nanofibers. These observation shows that spider-wave-like RGO/nylon-6 nanocomposite can be utilized for the future electronic and memory device applications.

\section{Conclusion}

We successfully demonstrated the indirect route of fabrication of RGO loaded polymer fibers using combined process of electrospinning and hydrothermal treatment. Good dispersion of GO sheets through nylon-6 solution could form spider-wave-like nano-nets during electrospinning and GO sheets present on fibers were converted to RGO by hydrothermal treatment. The incorporation of GO sheets through electrospun fibers and their reduction during hydrothermal treatment were confirmed by TEM, FT-IR, and Raman spectroscopy. The electrical characteristics of pristine nylon-6, GO/nylon-6, and RGO/nylon-6 were investigated. It was found that $\mathrm{RGO} /$ nylon- 6 composite mat had highest electrical conductivity. The significant enhanced electrical properties of RGO/nylon- 6 composite nanofibers compared to the pristine nylon- 6 fibers can be utilized for future nano-device and biosensor applications.

\section{Acknowledgment}

One of the authors Hem Raj Pant kindly acknowledges the financial support from the research fund of Chonbuk National University Grant Fellow Project 2012 (Research Associate Program) as well as a grant from the Korean Ministry of Education, Science and Technology (MIST) through the National Research Foundation (NRF) (Project no 2012-0001611 and 2012-013423). We would also like to thank Centre for University Research Facility (CURF) and
KBSI Jeonju branch, Chonbuk National University for BioTEM and FE-SEM analysis, respectively.

\section{References}

1. S. Ramakrishna, K. Fujihara, W. E. Teo, T. C. Lim, and Z. Ma, World Scientific Pub., Singapore, 2005.

2. A. Greiner and J. H. Wendorff, Angew. Chem. Inter. Ed., 46, 5670 (2007).

3. N. Bhardwaj and S. C. Kundu, Biotech. Adv., 28, 325 (2010).

4. S. Y. Jang, V. Seshadri, M. S. Khil, A. Kumar, M. Marquez, P. T. Mather, and G. A. Sotzing, Adv. Mater., 17, 2177 (2005).

5. W. A. Daoud, J. H. Xin, and Y. S. Szeto, Sensor Actuat. BChem., 109, 329 (2005).

6. B. Ding, X. Wang, J. Yu, and M. Wang, J. Mater. Chem., 21, 12784 (2011).

7. K. T. Nam, H. R. Pant, J. W. Jeong, B. Pant, B. Kim, and H. Y. Kim, Polym. Degrad. Stabil., 96, 1984 (2011).

8. H. R. Pant, M. P. Bajgai, K. T. Nam, K. H. Chu, S. Park, and H. Y. Kim, Mater. Lett., 64, 2087 (2010).

9. H. R. Pant, M. P. Bajgai, K. T. Nam, Y. A. Seo, D. R. Pandeya, S. T. Hong, and H. Y. Kim, J. Haz. Mater., 185, 124 (2011).

10. N. A. M. Barakat, M. A. Kanjwal, F. A. Sheikh, and H. Y. Kim, Polymer, 50, 4389 (2009).

11. H. R. Pant, K. Nam, H. Oh, G. Panthi, H. Kim, B. Kim, and H. Y. Kim, J. Colloid. Interf. Sci., 364, 107 (2011).

12. H. R. Pant, W. Baek, K. Nam, I. Jeong, N. A. M. Barakat, and H. Y. Kim, Polymer, 52, 4851 (2011).

13. H. R. Pant, M. P. Bajgai, C. Yi, R. Nirmala, K. T. Nam, W. Baek, and H. Y. Kim, Colloid. Surface. A, 370, 87 (2010).

14. H. R. Pant, C. H. Park, L. D. Tijing, A. Amarjargal, D. H. Lee, and C. S. Kim, Colloid. Surface. A, 407, 121 (2012).

15. N. L. Lala, V. Thavasi, and S. Ramakrishna, Sensors, 9, 86 (2009).

16. F. A. Sheikh, N. A. M. Barakat, M. A. Kanjwal, S. J. Park, Hern Kim, and H. Y. Kim, Fiber. Polym., 11, 384 (2010).

17. F. A. Sheikh, T. Cant, J. Macossay, and H. Kim, Sci. Advan. Mater., 3, 216 (2011).

18. Z. Zhou and X. F. Wu, J. Power Sources, 222, 410 (2013).

19. M. J. Allem, V. C. Tung, and R. B. Kaner, Chem. Rev., 110, 132 (2010).

20. A. K. Geim, Science, 324, 1530 (2009).

21. J. S. Kim, S. Hong, D. W. Park, and S. E. Shim, Micromol. Res., 18, 558 (2011).

22. S. Park, J. An, R. D. Piner, I. Jung, D. Yang, A. Velamakanni, S. T. Nguyen, and R. S. Ruoff, Chem. Mater, 20, 6592 (2008).

23. W. S. Hummers and R. E. Offeman, J. Am. Chem. Soc., 80, 1339 (1958).

24. H. M. Etmimi and R. D. Sanderson, Macromolecules, 44, 8504 (2011).

25. H. Dong, D. Wang, G. Sun, and J. P. Hinestroza, Chem. 
Mater, 20, 6627 (2008).

26. C. Nethravathi and M. Rajamathi, Carbon, 46, 1994 (2008).

27. H. Zhang, X. Lv, Y. Li, Y. Wang, and J. Li, ACS Nano, 4, 380 (2009).

28. D. R. Dreyer, S. Murali, Y. Zhu, R. S. Ruoff, and C. W. Bielawski, J. Mater. Chem., 21, 3443 (2011).

29. I. K. Moon, J. Lee, R. S. Ruoff, and H. Lee, Nature
Commun., 1, 1 (2010).

30. V. S. Dilimon and S. Sampath, Thin Solid Films, 519, 2323 (2011).

31. J. S. Jeong, S. Y. Jeon, T. Y. Lee, J. H. Park, J. H. Shin, P. S. Alegaonkar, A. S. Berdinsky, and J. B. Yoo, Diamond Related Mater., 15, 1839 (2006). 